\title{
The Study on the Operating Efficiency of Rural Banks Based on DEA Model: A Case of Jiangsu Province
}

\author{
Xu Lingjuan ${ }^{1}$, Wang Yanjun $^{1} \&$ Zhu Huailei ${ }^{2}$ \\ ${ }^{1}$ College of Economics and Management, Nanjing University of Aeronautics and Astronautics, China \\ ${ }^{2}$ Nanjing Pukou Jingfa County Bank, China \\ Correspondence: Xu Lingjuan, College of Economics and Management, Nanjing University of Aeronautics and \\ Astronautics, China. Tel: 86-137-7052-2735. E-mail: Linda_xu@ nuaa.edu.cn
}

Funded projects: Social Science Foundation of Jiangsu Province (15EYB007); Graduate innovation base (Lab) open foundation of Nanjing University of Aeronautics and Astronautics (kfjj20160904).

Received: May 25, 2017

doi:10.5539/ijef.v9n8p212
Accepted: July 14, 2017

Online Published: July 20, 2017

\begin{abstract}
The paper takes Jiangsu province as example in Yangtze River Delta, which is economically developed regions. According to previous research and characteristics of rural banks in Jiangsu Province, the input indexes are selected as the number of employees, the number of outlets, total deposits, business and management fees. And the output indexes include total loans, net interest income and net profit. Using DEA model to analyze the operating efficiency of the 65 rural banks in 2016, the paper compares the operating efficiency in different regions and different types of originating bank. The analysis shows that, compared with the central and northern Jiangsu, operating efficiency of rural banks in southern Jiangsu is generally high. The comprehensive technical efficiency value of sample banks that originated by the state-owned banks and joint-stock banks is significantly higher than that originated by rural commercial banks and city commercial banks. Finally, the paper puts forward some suggestions on how to improve the operating efficiency of rural banks.
\end{abstract}

Keywords: rural bank, DEA model, operation efficiency, pure technical efficiency, scale efficiency

\section{Introduction}

As one of new rural financial institutions in China, rural banks develop rapidly. There have been more than 1300 rural banks since the first rural bank established in 2007. However, in the early stage of rural banks, development is not plain sailing and shortcomings usually exists. Different from traditional commercial banks and rural financial institutions, rural banks have limited capital and deposit sources, lack innovation of security and mortgage. In addition, financial products and services are relatively single and low income from credit products. Therefore, it is generally considered that its efficiency is lower than that of general commercial banks (Jiheng, 2014).

Operating efficiency means how to obtain the maximum reward with limited input in a certain external market environment and technical level. The bank's operating efficiency reflects its effective allocation of resources, which is the general name of the bank's market competitiveness, capacity between input and output and ability of sustainable development. Currently, the research methods of domestic and foreign scholars on the efficiency of commercial banks usually are the financial ratio analysis method and the effective frontier method. The data envelopment analysis (DEA) is one of efficient frontier analysis methods, proposed by Charnes, Cooper and Rhodes (1978). Sherman and Gold (1985) applied DEA in evaluating the efficiency of branches for the first time, they took a sample of 14 branches of one savings bank in 1980 and evaluated operating efficiency of them. Since then, DEA has been widely used to measure the operational efficiency of commercial banks and other institutions.

Microfinance institutions such as rural banks rose late, accordingly, empirical research started relatively late due to the lack of comprehensive and systematic data.

Bassem (2008) used DEA to measure the efficiency of the 35 small loan institutions, found that the scale had a 
negative impact on efficiency. Mamiza et al. (2010) used DEA method to analyze the cost efficiency of 39 microfinance institutions in the Asia Africa region. The results showed that the efficiency of microfinance institutions dominated by banks may be better than that of non-governmental organizations.

At present, the research on the efficiency of banks in China is mainly concentrated in the mature financial institutions, such as state-owned banks and joint-stock banks. The empirical research on the operating efficiency of rural banks is relatively small. Wu Shaoxin (2009) used super efficiency DEA model to analyze four rural banks in China, he concluded that low operating efficiency is related to low deposit scale, poor profitability of the primary business, weak capital strength. Xu Shufang, Yu Chuchu (2016) calculated financial efficiency value of 72 rural banks by using DEA method, results showed that financial efficiency value of China's rural bank was generally low at the present stage.

Hu Zhuzhi (2015) selected 803 rural banks in China as a sample, used the method of DEA to estimate the overall efficiency of China's rural banks. She found that the efficiency of rural banks was low generally, the efficiency of the central and western regions is higher than that of the East, and the efficiency of the samples which rural financial institutions is higher than those originated by non-rural financial institutions.

China's rural banks are in the initial stage of development, compared with other financial institutions, they are still immature.

In addition, the number of rural banks is small and most of them are unlisted, so there is no regular external financial information disclosure. Lack of business data brings many obstacles to the study of operating efficiency of rural banks. The present empirical research about operating efficiency of rural banks is very little and focus on China's central and western provinces. There is little empirical research on rural banks in the Yangtze River Delta, which is economically developed. Jiangsu Province, one of the most economically developed regions in China, ranked second in the total amount of GDP in 2016. On behalf of small and micro finance, rural banks in Jiangsu also develop very rapidly. From the regional perspective, this paper analyzes the operating efficiency of the rural banks in Jiangsu Province, and expounds from three aspects (pure technical efficiency, scale efficiency and comprehensive technical efficiency) that previous studies are less relevant. Therefore, this paper selects Jiangsu Province as the representative, makes the study on operating efficiency of rural banks based on the DEA model.

\section{Overview of DEA Model}

Data envelopment analysis (DEA), as a linear programming technique, makes the comparison on efficiency of many enterprises providing similar products and services by considering multiple inputs and outputs explicitly. The DEA model assumes that the each decision unit has $m$ input variables and $\mathrm{s}$ output variables and compares efficiency of the $\mathrm{N}$ decision making units. Decision making unit $\mathrm{J}$ is denoted as $D U M_{j}$.

Decision making unit $\mathrm{j}$ is denoted as $D U M_{j}, 1 \leq j \leq n$.

Let $x_{i j}$ be the input amount of $D U M_{j}$ to the i, $1 \leq r \leq m$; Let $y_{r j}$ be the output amount of $D U M_{j}$ to the $\mathrm{r}, 1 \leq r \leq s$. Then, Input and output of $D U M_{j}$ are $X_{j}=\left(x_{1 j}, x_{2 j}, \cdots, x_{m j}\right)^{T} \geq 0$ and $Y_{j}=\left(y_{1 j}, y_{2 j}, \cdots, y_{m j}\right)^{T} \geq$ 0 .

The efficiency evaluation index is:

$$
h_{j}=\frac{u^{T} Y_{j}}{v^{T} X_{j}}, j=1,2, \cdots, n
$$

We can appropriately choose the weight coefficient $\mathrm{u}$ and $\mathrm{v}$ that makes $h_{j} \leq 1$. Taking it as the constraint condition, the CCR model is constructed:

$$
\begin{gathered}
\operatorname{Max} \frac{u^{T} Y_{0}}{v^{T} X_{0}}=h_{0} \\
\text { s.t. } \frac{u^{T} Y_{j}}{v^{T} X_{j}} \leq 1, u \geq 0, v \geq 0, j=1,2, \cdots, n
\end{gathered}
$$

On the Charnes-Cooper transform, the dual programming model generated by the linear programming model is: Min $\theta$

$$
\begin{array}{cl}
\text { s.t. } & \sum_{r=1}^{n} X_{r} \lambda_{r} \leq \theta X_{j} \\
& \sum_{r=1}^{n} Y_{r} \lambda_{r} \leq Y_{j} \\
\lambda_{r} \geq 0, r=1,2, \cdots, n
\end{array}
$$


$\theta$ is the efficiency value of $D U M_{j}, 0 \leq \theta \leq 1$. When $\theta$ equals $1, D U M_{j}$ is effective. Otherwise $D U M_{j}$ is ineffective. When adding a convexity assumption that $\sum_{i=1}^{n} \lambda_{i}=1$, The BCC model with variable returns to scale is obtained after modified.

\section{Sample and Index Selection}

\subsection{Sample Selection}

There are 74 rural banks currently in Jiangsu province. In order to study the operating efficiency of rural banks in Jiangsu Province systemically, we eliminate 9 rural banks whose index is not available. Taking into account the integrity and availability of data, this paper selects 65 rural banks in Jiangsu Province as the sample.

The sample includes 22 rural banks in southern Jiangsu, 17 rural banks in central Jiangsu and 26 rural banks in northern Jiangsu, so that makes the sample extensive and representative.

Sample data is cross-sectional data in 2016, including the number of employees, the number of bank outlets, the number of paid in registered capital, business and management fees, total deposits, total loans, net interest income and net profit of the 65 rural banks. The data of this paper is nonpublic information that comes from the internal database of the bank.

\subsection{Index Selection}

The core of using DEA model to calculate the efficiency of banks is the choice of input and output variables. According to the existing literature, there are three methods of variable selection, Production Approach, Intermediate Approach and Asset Approach. Both of these three methods have some rationality and limitations. In production approach, bank is thought as a manufacturer that producing various types of financial products. Capital and labor inputs, output the number of account and loans. The flaw is that the difference between each account and each loan does not been reflected. Intermediate approach considers the bank as an intermediary to convert savings into investment, it inputs labor and capital, takes the amount of deposits and loans as its output. The flaw is that banks' revenues and other businesses have been ignored. Asset approach only selects the asset items in the balance sheet as output indicators, deposits are not included in the output as liabilities. The disadvantage is that the asset items is limited by the balance sheet and it ignore the off balance sheet items.

Mainly clients of rural banks are related to " 3 farming", so they has the characteristics of small size, low threshold for the establishment. The business of them is relatively simple, mainly concentrated in the deposit and loan, rarely carry out agency, trust, consulting, settlement and other intermediary business. Therefore, compared with the deposit and loan interest rates, fee income accounts for a small part of revenue.

In this paper, based on the existing research results, we choose Intermediate approach and Asset approach. Considering financial intermediary property of the rural bank and the availability of data, the input indicators are selected as the number of employees, the number of business outlets, total deposits, business and management fees, registered capital. The output indicators includes total loans, net interest income and net profit.

After the preliminary correlation analysis, the registered capital as input indicator, has very low correlation with the 3 output indicators, thus eliminates the registered capital.

\section{Analysis of the Empirical Results}

Deap2.1 software is used to calculate the panel data of 65 rural banks in Jiangsu province in 2016, and the results are analyzed from the following three aspects: pure technical efficiency, scale efficiency and comprehensive technical efficiency.

\subsection{Pure Technical Efficiency}

Management and technology of the bank affect pure technical efficiency. Through the calculation of the DEA model, there are 29 rural banks that have pure technical efficiency value of 1, accounting for $44.62 \%$ of the total sample. The average value of pure technical efficiency is 0.856 . As can be seen from Figure 1, in addition to 29 rural banks pure technical efficiency value of 1 of, the rest of the samples are more evenly distributed in the 0.4-0.9 range. Although the average technical efficiency of the sample banks is at a high level, it does not mean that most of the rural banks can achieve the rational allocation of resources at the current level of technology. It is mainly reflected in the mode of operation and management.

Through the investigation, most of the managers of the rural banks in Jiangsu Province are directly appointed by the originating banks, and their management mode is basically based on the previous ideas. For rural banks' features that less capital, small and scattered customer service, it have not been significantly changed. The unsuitable management mode makes the pure technical efficiency of sample banks less than 1 . 
From the geographical distribution, there are 15 rural banks from South of Jiangsu that have pure technical efficiency value of 1 , accounting for the proportion of the region of $51.72 \%$. The average pure technical efficiency is the highest too, 0.9147 .

From the types of originating banks of view, in the main, there are 13 rural banks issued by rural commercial banks that achieve pure technical efficiency. Although the number of the most, but the proportion is only $39.39 \%$. The state-owned banks have 5 ones pure technical efficiency value of 1 , accounted for up to $62.5 \%$ in the same type.
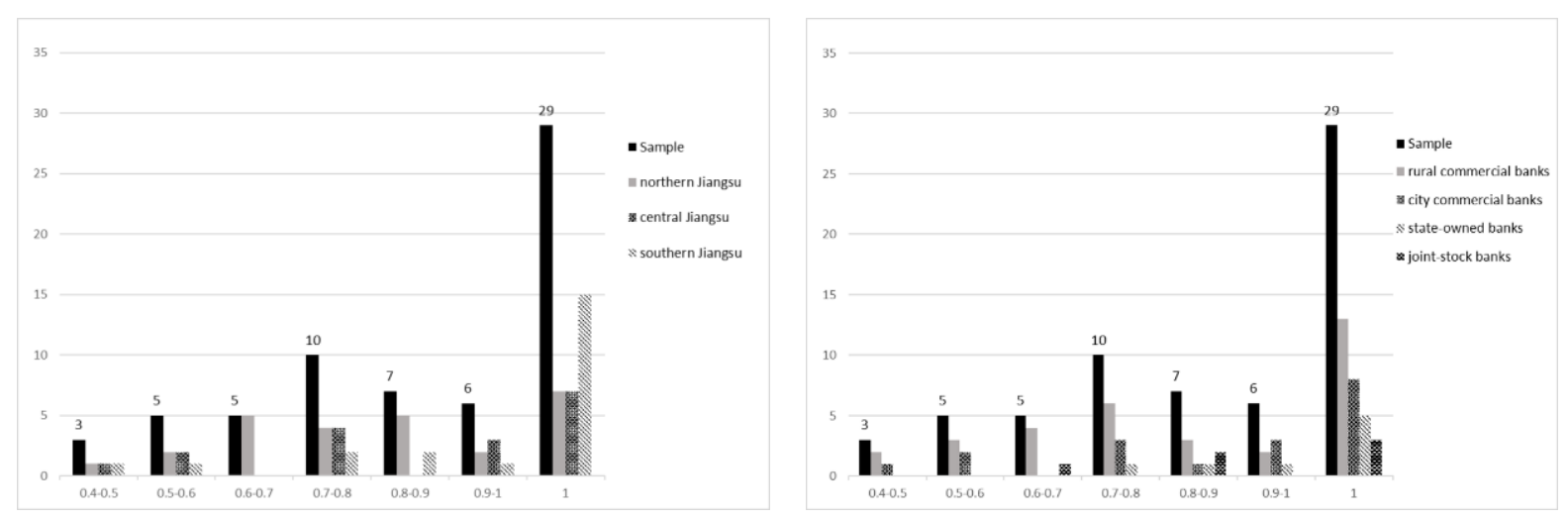

Figure 1. Pure technical efficiency value frequency distribution

\subsection{Scale Efficiency}

Scale efficiency refers to the difference between the existing scale and the optimal size when the bank management level and technical level are unchanged. The scale efficiency is mainly affected by the size of the bank, the sample bank can adjust the scale of operation from the scale efficiency value is increasing or decreasing. Through the calculation of the DEA model, there are 13 rural banks that have scale efficiency value of 1 , accounting for $20 \%$ of the total sample. Although the number of the banks having scale efficiency value of 1 is far less than that having pure technical efficiency value of 1 , most of the sample bank's scale efficiency values are concentrated near 1 . The average scale efficiency value of the sample is 0.875 . It is higher than the pure technical efficiency, which indicates that the sample is better in scale efficiency.

In terms of geographical distribution, the average scale efficiency of rural banks in northern Jiangsu is the highest, which is 0.8924 . From the types of originating banks of view, the average scale efficiency value of the samples which originated by the state-owned and joint-stock banks is higher than that originated by rural commercial banks and city commercial banks.

In addition, among the sample of banks that scale efficiency value is less than 1, there are $49.23 \%$ of them that shows in the decreasing returns to scale, which means that nearly half of the sample having the problem of excessive size. There are many reasons for diminishing returns to scale, mainly due to the large scale of production, which makes it difficult to get effective coordination between input and output.

One of the reasons is originating banks blindly pursue scale expansion, in order to occupy the market rapidly. In the sample of rural banks, the number of the originating bank is a rural commercial bank or a city commercial bank is a total of 51. This shows the great enthusiasm of the regional financial institutions to expand rural financial business. It also brings the phenomenon that a lot of rural banks getting together in the same area. Another reason is from the intervention of the local government, local government takes investment and promotion as performance, so encourages rural banks to expand.

This gives the rural bank's business philosophy the pace of preference and the concept of scale first, making the size of rural banks generally too large. In fact, rural banks are related to " 3 farming", small scale is more suitable for its development path of specialization and refinement, in favor of improving the efficiency of scale. 


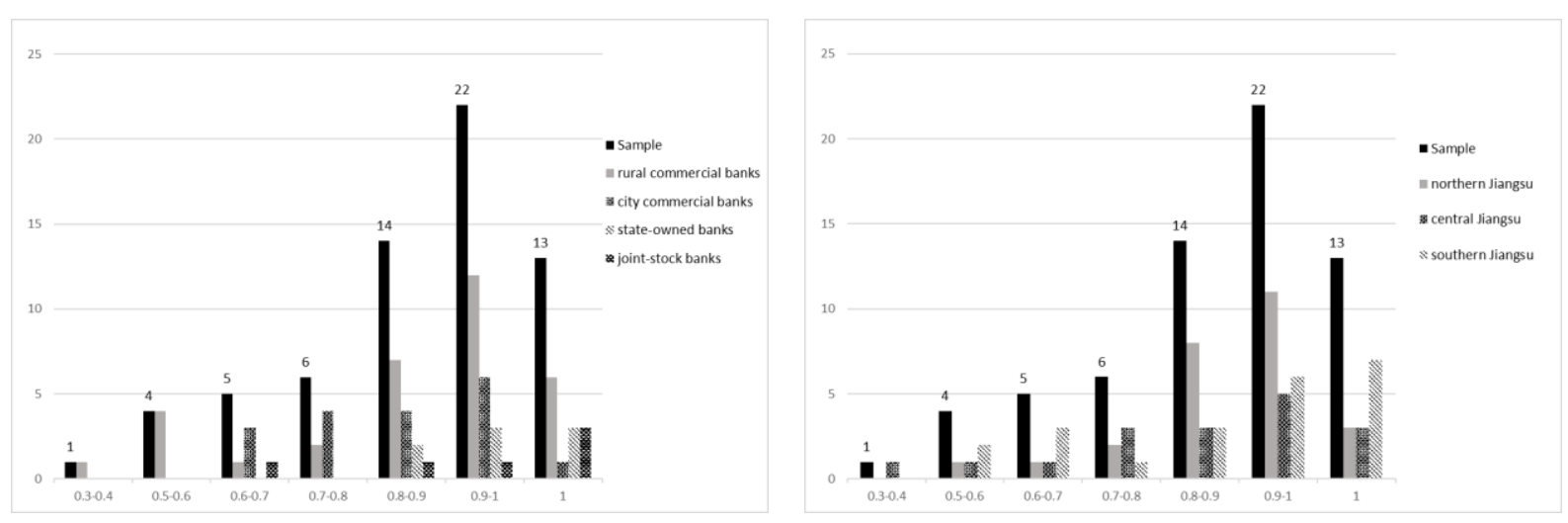

Figure 2. Scale efficiency frequency distribution

\subsection{Comprehensive Technical Efficiency}

The comprehensive technical efficiency is the comprehensive evaluation of the ability of resource allocation and utilization. The value is equal to the product of pure technical efficiency and scale efficiency. The efficiency value is 1 , which indicates that the pure technical efficiency and scale efficiency are both effective.

Generally, through the calculation of the DEA model, there are 12 rural banks that have comprehensive technical efficiency value of 1 , accounting for $18.46 \%$ of the total sample. The average value of pure technical efficiency is 0.744 .

From the geographical distribution, compared with the central and northern Jiangsu, the rural banks in southern Jiangsu are generally higher in operating efficiency. The average of comprehensive technical efficiency of southern Jiangsu area is significantly higher than the average level of Jiangsu province. Among the 12 rural banks that have comprehensive technical efficiency value of 1, there are 7 banks in southern Jiangsu, 3 banks in central Jiangsu and 2 banks in northern Jiangsu. The proportion of banks in each region is $31.81 \%, 17.65 \%$ and $7.69 \%$. In terms of the proportion and quantity, South of Jiangsu area is superior to the central and northern Jiangsu.

Table 1 . The average efficiency value by geographical distribution

\begin{tabular}{cccc}
\hline Geographical distribution & Mean of pure technical efficiency & Mean of scale efficiency & Mean of comprehensive technical efficiency \\
\hline Southern Jiangsu & 0.9147 & 0.8769 & 0.8021 \\
Central Jiangsu & 0.8532 & 0.8446 & 0.7206 \\
Northern Jiangsu & 0.8075 & 0.8924 & 0.7161 \\
Jiangsu & 0.856 & 0.875 & 0.744 \\
\hline
\end{tabular}

Table 2. The bank comprehensive effective quantity and distribution - according to geographical distribution

\begin{tabular}{ccccccc}
\hline $\begin{array}{c}\text { Geographical } \\
\text { distribution }\end{array}$ & $\begin{array}{c}\text { The number } \\
\text { of banks }\end{array}$ & Proportion & $\begin{array}{c}\text { The number of banks that } \\
\text { have effective DEA }\end{array}$ & $\begin{array}{c}\text { Proportion in } \\
\text { each region }\end{array}$ & $\begin{array}{c}\text { The number of banks that } \\
\text { have ineffective DEA }\end{array}$ & $\begin{array}{c}\text { Proportion in } \\
\text { each region }\end{array}$ \\
\hline Southern Jiangsu & 22 & $33.85 \%$ & 7 & $31.81 \%$ & 15 & $68.19 \%$ \\
Central Jiangsu & 17 & $26.15 \%$ & 3 & $17.65 \%$ & 14 & $82.35 \%$ \\
Northern Jiangsu & 26 & $40.00 \%$ & 2 & $7.69 \%$ & 24 & $92.31 \%$ \\
Total & 65 & $100.00 \%$ & 12 & $18.46 \%$ & 53 & $81.54 \%$ \\
\hline
\end{tabular}

The main reason is the rapid economic development in South of Jiangsu, with a high level of financial agglomeration. What's more, the quality of bank employees, corporate governance and business management mode in southern Jiangsu are more mature. There are more obvious advantages of human resources and geographical location.

Based on vast territory and abundant resources, northern Jiangsu has a large rural population, making the rural financial demand more urgent. From the number of rural banks can be seen, there are $40 \%$ rural banks from the northern region, so the scale efficiency is higher. However, due to the underdevelopment of the economy, the 
northern Jiangsu has not achieved systematic improvement in management, and the low efficiency of pure technology leads to the low level of overall efficiency. The area of the central Jiangsu is small, development is limited by the number of rural banks, and the scale efficiency is low.

Table 3. The average efficiency value by the types of originating banks

\begin{tabular}{cccc}
\hline The types of originating banks & Mean of pure technical efficiency & Mean of scale efficiency & Mean of comprehensive technical efficiency \\
\hline Rural commercial banks & 0.8219 & 0.8642 & 0.6975 \\
City commercial banks & 0.8654 & 0.8422 & 0.7277 \\
State-owned banks & 0.9471 & 0.9628 & 0.9136 \\
Joint-stock banks & 0.8923 & 0.9125 & 0.8142 \\
\hline
\end{tabular}

Table 4. The bank comprehensive effective quantity and distribution - according to the types of originating banks

\begin{tabular}{ccccccc}
\hline $\begin{array}{c}\text { Types of originating } \\
\text { banks }\end{array}$ & $\begin{array}{c}\text { The number } \\
\text { of banks }\end{array}$ & Proportion & $\begin{array}{c}\text { The number of banks that } \\
\text { have effective DEA }\end{array}$ & $\begin{array}{c}\text { Proportion in } \\
\text { each type }\end{array}$ & $\begin{array}{c}\text { The number of banks that } \\
\text { have ineffective DEA }\end{array}$ & $\begin{array}{c}\text { Proportion in } \\
\text { each type }\end{array}$ \\
\hline Rural commercial banks & 33 & $50.77 \%$ & 5 & $15.15 \%$ & 28 & $84.85 \%$ \\
City commercial banks & 18 & $27.69 \%$ & 1 & $5.56 \%$ & 17 & $94.44 \%$ \\
State-owned banks & 8 & $12.31 \%$ & 3 & $37.50 \%$ & 5 & $62.50 \%$ \\
Joint-stock banks & 6 & $9.23 \%$ & 3 & $50.00 \%$ & 3 & $50.00 \%$ \\
Total & 65 & $100.00 \%$ & 12 & $18.46 \%$ & 53 & $81.54 \%$ \\
\hline
\end{tabular}

From the types of originating banks of view, originating banks of the sample includes 33 rural commercial banks, 18 city commercial banks, 8 the state-owned banks and 6 joint-stock banks. Among the banks that the value of comprehensive technical efficiency is 1 , there are 5 rural commercial banks, 1 city commercial banks, 3 state-owned banks and 3 joint-stock banks. Proportion of each type is $15.15 \%, 5.56 \%, 37.5 \%$ and $50 \%$ respectively. The comprehensive technical efficiency value of sample banks that originated by the state-owned banks and joint-stock banks is significantly higher than that originated by rural commercial banks and city commercial banks. The results show that the rural banks, which rely on the state-owned banks and joint-stock banks, have followed the traditional bank's standardized management model in the corporate governance and management. From the perspective of input and output, the state-owned and joint-stock ones can achieve high efficiency value.

In the recruitment of staff and attract talent, the banks issued by rural commercial banks and city commercial banks fail to show a greater advantage, such as providing higher salaries, better occupation prospects. Therefore, in the process of improving the management mode, these banks are lack of high-quality management and business personnel, operating efficiency is relatively low.

\section{Conclusion and Suggestion}

The paper takes Jiangsu province as example in Yangtze River Delta, which is economically developed regions. According to previous research and characteristics of rural banks in Jiangsu Province, the input indexes are selected as the number of employees, the number of outlets, total deposits, business and management fees. And the output indexes include total loans, net interest income and net profit. Using DEA model to analyze the operating efficiency of the 65 rural banks in 2016, the following conclusions are drawn.

Compared with the central and northern Jiangsu, the rural banks in southern Jiangsu are generally higher in operating efficiency; The comprehensive technical efficiency value of sample banks that originated by the state-owned banks and joint-stock banks is significantly higher than that originated by rural commercial banks and city commercial banks.

The following suggestions are put forward.

\section{(1) Perspective of rural banks}

Rural banks need to identify the location of the rural market, choose the scale of development according to local conditions. They need to achieve specialization and refinement in the development through a variety of ways, such as continuous innovation and development of financial products, expanding the scope of the credit business and gradually establishing a rural bank brand effect efforts. Preventing excessive investment and blind expansion is also important to improve the scale efficiency. In addition, due to the establishment of the rural banks is short, farmers have a lower degree of recognition. By comparison, the rural credit cooperatives, rural cooperative 
banks and other rural financial institutions operating for many years, has accumulated a wealth of experience, farmers recognition is also higher. Rural banks can strengthen cooperation with these financial institutions, introduce their business mode and customer resources.

\section{(2) Perspective of originating bank}

As the main holding of the rural bank, originating bank plays a vital role in management. Mature management system can be introduced into the early management of rural banks to help them establish effective management mechanism. Rich credit experience and business model can provide reference for rural banks, according to the different needs of farmers to design different products. The originating bank can use the existing platform to promote the visibility of rural banks and enhance acceptance of customer, in order to ease the problem of limited funds. At the technical level, mature network system and advanced software programs of the originating bank can help rural banks to carry out routine service management.

\section{(3) Perspective of regional development}

The differences between regions are derived from many aspects. Through the establishment of a more comprehensive inter-regional financial information system in Jiangsu Province, we can strengthen the communication between regions and reduce the information asymmetry between the developed and underdeveloped areas. The faster financial information spread, the higher level of financial knowledge in rural areas has. As a result, the acceptance of new financial institutions such as rural banks is higher. It will make it easy for rural bank to attract high-quality personnel and promote their business. Better regional layout and development level of rural banks, will improve operating efficiency.

\section{References}

Bassem, B. S. (2008). Efficiency of Microfinance Institutions in the Mediterranean: An Application of DEA. Transition Studies Review, 15(2), 343-354. https://doi.org/10.1007/s11300-008-0012-7

Charnes, A., Cooper, W. W., \& Rhodes, E. (1978). Measuring the efficiency of decision making units. European Journal of Operational Research, 2(6), 429-444. https://doi.org/10.1016/0377-2217(78)90138-8

Haq, M., Skully, M., \& Pathan, S. (2010). Efficiency of Microfinance Institutions: A Data Envelopment Analysis. Asia-Pacific Financial Markets, 17(1), 63-97. https://doi.org/10.1007/s10690-009-9103-7

Shaoxin, W., Jianhua, L., \& Chuanhua, X. (2009). Research on the operating efficiency of rural banks based on DEA super efficiency model. Finance \& Trade Economics, (12), 45-49.

Sherman, H. D., \& Gold, F. (1985). Branch Operating Efficiency: Evaluation with Data Envelopment Analysis. Journal of Banking \& Finance, 9(2), 297-315. https://doi.org/10.1016/0378-4266(85)90025-1

Shufang, X., \& Chuchu, Y. (2016). Study on the factors affecting the financial efficiency of rural banks in China -- Based on the perspective of macroeconomic environment. Macroeconomics, (05), 119-127.

Wang, J., Li, F., \& Yu, Y. (2014). Problems and Countermeasures in the development of rural banks in China. Economic Review, (6),107-110.

Zhuzhi, H., Yicong, H., \& Kaiyao, Q. (2015). Research on the efficiency of rural banks in China based on DEA model. Reform of Economic System, (2), 97-102.

\section{Appendix 1}

\begin{tabular}{cccc}
\hline \multicolumn{4}{c}{ The following are names of 65 rural banks: } \\
\hline 1 & Nanjing Pukou Jingfa County Bank & 34 & Gaochun Wujiangzui Jianxin Rural Bank \\
2 & Jiangsu Lishui Mingfeng County Bank & 35 & Jiangsu Xishan Jianxin Rural Bank \\
3 & Wuxi Binghu Xingfu County Bank & 36 & JiangsuWujin Jianxin Rural Bank \\
4 & Changzhou Xinbei Zhongcheng Rural Bank & 37 & Suzhou BOC Fullerton Community Bank \\
5 & Jintan County Bank & 38 & Jiangsu Haimen Jianxin Rural Bank \\
6 & Suzhou Wuzhong Zhujiang Rural Bank & 39 & Jiangsu Taixing Jianxin Rural Bank \\
7 & Zhenjiang Runzhou Changjiang Rural Bank & 40 & Suining BOC Fullerton Community Bank \\
8 & Jurong Sunan Rural Bank & 41 & Xiangshui BOC Fullerton Community Bank \\
9 & Jiangsu Haian Yanhai Rural Bank & 42 & Jiangsu Jiangning BOS \\
10 & Jiangsu Qidong Zhujiang Rural Bank & 43 & Nanjing Liuhe Jiuyin County Bank \\
11 & Tongzhou Huashang Rural Bank & 44 & Huishan Mingtai Rural Bank of Jiangsu \\
12 & Hanjiang United Rural Bank & 45 & Yixing Yangxian \\
\hline
\end{tabular}




\begin{tabular}{lccc}
\hline 13 & Yangzhou Gaoyou Xingfu County Bank & 46 & Kunshan Lucheng County Bank \\
14 & Taizhou Gaogang Xingfu County Bank & 47 & Baode County Bank of Jiangsu Danyang \\
15 & Jiangsu Jingjiang Runfeng County Bank & 48 & Rudong Rongxing Village \& Township Bank \\
16 & Xinghua Sunan County Bank & 49 & Nantong Rugao Baoshang Rural Bank \\
17 & Jiangyan Xizhou County Bank & 50 & Jiangsu Hanjiang Mintai County Bank \\
18 & Jiangsu Fengxian Minfeng County Bank & 51 & Jiangsu Baoying Jincheng Village Bank \\
19 & Jiangsu Peixian Hanyuan County Bank & 52 & Jiangsu Yizheng Baoshang Rural Bank \\
20 & Jiangsu Tongshan Xizhou County Bank & 53 & Jiangdu Jiyin County Bank \\
21 & Jiangsu Xinyi Hanyuan County Bank & 54 & Jiangsu Jinhu Mintai County Bank \\
22 & Jiangsu Sunny Bank & 55 & Jiangsu Dongtai Chouzhou Rural Bank \\
23 & Jiangsu Ganyu Tongshang Rural Bank & 56 & Jiangsu SuyuDongwu County Bank \\
24 & Jiangsu Donghai ZRC Rural Bank & 57 & Jiangsu Shuyang Dongwu County Bank \\
25 & Jiangsu Guanyun Minfeng County Bank & 58 & Jiangsu Siyang Dongwu County Bank \\
26 & Jiangsu GuannanMinfeng County Bank & 59 & Jiangsu Sihong Dongwu County Bank \\
27 & Huaian Huaiyin Xingfu County Bank & 60 & Jiangyin SPD Rural Bank \\
28 & Huaian Qingpu Xingfu County Bank & 61 & Liyang SPD Rural Bank \\
29 & Jiangsu Lianshui Taishang County Bank & 62 & Taicang Minsheng Rural Bank \\
30 & Jiangsu Hongze Golden Sunshine County Bank & 63 & Yangzhong Evergrowing Rural Bank \\
31 & Jiangsu Sheyang Taishang County Bank & 64 & Jiangsu Huaian Everbright Village Bank \\
32 & Jiangsu Dafeng Jiangnan County Bank & 65 & Funing Minsheng Rural Bank \\
33 & Suqian Sucheng CRC Rural Bank & & \\
\hline
\end{tabular}

\section{Appendix 2}

\begin{tabular}{|c|c|c|c|c|c|c|c|c|}
\hline \multicolumn{9}{|c|}{ The following data of the sample is in 2016 . } \\
\hline $\begin{array}{c}\text { Serial } \\
\text { number }\end{array}$ & total loans & $\begin{array}{c}\text { net interest } \\
\text { income }\end{array}$ & $\begin{array}{c}\text { net } \\
\text { profit }\end{array}$ & the registered capital & $\begin{array}{c}\text { total } \\
\text { deposits }\end{array}$ & $\begin{array}{c}\text { the number of } \\
\text { outlets }\end{array}$ & $\begin{array}{c}\text { the number of } \\
\text { employees }\end{array}$ & $\begin{array}{c}\text { business and } \\
\text { management fees }\end{array}$ \\
\hline 1 & 38196 & 2743 & 1002 & 10000 & 37134 & 2 & 39 & 1192 \\
\hline 2 & 35166 & 2010 & 129 & 20000 & 42026 & 1 & 26 & 1190 \\
\hline 3 & 30902 & 2093 & 248 & 10000 & 63866 & 3 & 49 & 1772 \\
\hline 4 & 40149 & 2641 & 216 & 10000 & 70721 & 2 & 46 & 1462 \\
\hline 5 & 29913 & 2307 & 653 & 8000 & 32853 & 1 & 23 & 864 \\
\hline 6 & 23279 & 660 & 102 & 15000 & 10018 & 1 & 22 & 688 \\
\hline 7 & 69072 & 5544 & 891 & 10000 & 91501 & 5 & 127 & 3652 \\
\hline 8 & 30121 & 1551 & 130 & 10000 & 26220 & 1 & 51 & 919 \\
\hline 9 & 140530 & 6095 & 930 & 10000 & 141401 & 2 & 58 & 1940 \\
\hline 10 & 252985 & 10733 & 4067 & 13000 & 282666 & 6 & 114 & 3681 \\
\hline 11 & 46503 & 2071 & 471 & 20000 & 25278 & 1 & 27 & 1165 \\
\hline 12 & 149905 & 6806 & 3052 & 15000 & 184835 & 3 & 55 & 2414 \\
\hline 13 & 47408 & 2432 & 91 & 5100 & 23998 & 4 & 59 & 1453 \\
\hline 14 & 50023 & 2564 & 803 & 20000 & 40348 & 1 & 23 & 1115 \\
\hline 15 & 101839 & 6508 & 2648 & 15000 & 133290 & 3 & 107 & 3978 \\
\hline 16 & 402839 & 16914 & 6734 & 25923 & 468189 & 7 & 179 & 6557 \\
\hline 17 & 52006 & 3472 & 735 & 15000 & 53493 & 3 & 70 & 1926 \\
\hline 18 & 98704 & 6295 & 124 & 13500 & 110813 & 4 & 86 & 3687 \\
\hline 19 & 25864 & 1793 & 355 & 20000 & 45615 & 1 & 35 & 1055 \\
\hline 20 & 141935 & 6862 & 2823 & 11000 & 153768 & 2 & 49 & 2328 \\
\hline 21 & 58978 & 2931 & 714 & 12500 & 45262 & 1 & 31 & 1008 \\
\hline 22 & 110793 & 4508 & 607 & 18000 & 71405 & 4 & 76 & 2932 \\
\hline 23 & 94458 & 4629 & 953 & 10000 & 118568 & 4 & 68 & 1782 \\
\hline 24 & 40056 & 3245 & 1277 & 10000 & 90138 & 2 & 38 & 1523 \\
\hline 25 & 63960 & 3128 & 602 & 10000 & 67438 & 4 & 64 & 2009 \\
\hline 26 & 72033 & 3255 & 623 & 10000 & 73536 & 5 & 84 & 2582 \\
\hline 27 & 56543 & 2530 & 89 & 10000 & 52328 & 3 & 64 & 1593 \\
\hline 28 & 72793 & 3498 & 1022 & 10000 & 72740 & 1 & 30 & 1401 \\
\hline 29 & 126984 & 7848 & 1828 & 11500 & 179732 & 7 & 135 & 3999 \\
\hline
\end{tabular}




\begin{tabular}{|c|c|c|c|c|c|c|c|c|}
\hline 30 & 75124 & 5664 & 1015 & 20000 & 82295 & 3 & 81 & 3060 \\
\hline 31 & 38059 & 2226 & 735 & 10000 & 43892 & 1 & 39 & 1044 \\
\hline 32 & 128296 & 8994 & 1538 & 10000 & 158003 & 6 & 106 & 4403 \\
\hline 33 & 16413 & 870 & 32 & 3000 & 16908 & 1 & 40 & 672 \\
\hline 34 & 51190 & 3210 & 1234 & 18000 & 53003 & 3 & 58 & 1438 \\
\hline 35 & 25591 & 1384 & 70 & 3175 & 18120 & 1 & 32 & 837 \\
\hline 36 & 81435 & 5333 & 1605 & 13498 & 105324 & 3 & 54 & 1374 \\
\hline 37 & 43297 & 1947 & 22 & 10000 & 20569 & 2 & 35 & 905 \\
\hline 38 & 38433 & 1896 & 863 & 10000 & 33234 & 1 & 21 & 767 \\
\hline 39 & 20776 & 1284 & 256 & 15000 & 18737 & 2 & 23 & 724 \\
\hline 40 & 71172 & 5537 & 626 & 5000 & 113881 & 3 & 74 & 2184 \\
\hline 41 & 68227 & 3504 & 359 & 5000 & 89250 & 6 & 66 & 2310 \\
\hline 42 & 64461 & 2532 & 62 & 10000 & 18165 & 1 & 20 & 704 \\
\hline 43 & 49473 & 3690 & 1295 & 5000 & 62490 & 3 & 65 & 1568 \\
\hline 44 & 42463 & 3061 & 321 & 10000 & 54926 & 5 & 53 & 1967 \\
\hline 45 & 55705 & 3587 & 719 & 10000 & 63382 & 7 & 97 & 2205 \\
\hline 46 & 17716 & 825 & 155 & 10000 & 15863 & 1 & 23 & 423 \\
\hline 47 & 53891 & 3352 & 540 & 6000 & 76341 & 3 & 47 & 1559 \\
\hline 48 & 48209 & 2490 & 479 & 5000 & 43292 & 2 & 40 & 1169 \\
\hline 49 & 53947 & 3564 & 518 & 5000 & 54378 & 3 & 55 & 1511 \\
\hline 50 & 63010 & 3779 & 566 & 10000 & 61082 & 2 & 51 & 1945 \\
\hline 51 & 20023 & 1892 & 262 & 3100 & 32142 & 4 & 62 & 1169 \\
\hline 52 & 23294 & 2028 & 457 & 3090 & 18262 & 3 & 54 & 1089 \\
\hline 53 & 46151 & 2887 & 1126 & 8000 & 55952 & 3 & 56 & 1583 \\
\hline 54 & 46145 & 2785 & 670 & 8000 & 84241 & 3 & 41 & 1063 \\
\hline 55 & 81137 & 5935 & 2322 & 8000 & 111760 & 5 & 87 & 2946 \\
\hline 56 & 29666 & 2587 & 896 & 4000 & 44103 & 2 & 47 & 1125 \\
\hline 57 & 95308 & 4894 & 1097 & 8500 & 130913 & 3 & 61 & 2402 \\
\hline 58 & 77891 & 5026 & 1161 & 5989 & 91614 & 3 & 59 & 2212 \\
\hline 59 & 98543 & 5184 & 1284 & 10000 & 99165 & 6 & 126 & 3069 \\
\hline 60 & 77441 & 5472 & 1946 & 10000 & 123231 & 5 & 88 & 2697 \\
\hline 61 & 20263 & 1226 & 76 & 3220 & 16145 & 1 & 28 & 849 \\
\hline 62 & 39311 & 3091 & 381 & 10000 & 56960 & 3 & 62 & 2150 \\
\hline 63 & 177045 & 12261 & 3520 & 10600 & 200218 & 9 & 168 & 6018 \\
\hline 64 & 54451 & 5041 & 2313 & 10000 & 90491 & 3 & 72 & 2303 \\
\hline 65 & 67408 & 6250 & 2306 & 10000 & 102820 & 4 & 69 & 2883 \\
\hline
\end{tabular}

Note. Based on the non-disclosure of the rural bank data, number of schedule 2 is not consistent with the number of schedule 1.

\section{Copyrights}

Copyright for this article is retained by the author(s), with first publication rights granted to the journal.

This is an open-access article distributed under the terms and conditions of the Creative Commons Attribution license (http://creativecommons.org/licenses/by/4.0/). 